\title{
Роль электрического тока в редокс-сорбции кислорода медьсодержащими нанокомпозитами
}

\author{
(C) 2020 Кравченко Т.А., Вахнин Д.Д., Чумакова А.В., Шевцова Е.А. \\ Воронежский государственный университет, Воронеж
}

Поступила в редакцию 12.07.2020 г.

DOI: $10.17308 /$ sorpchrom.2020.20/2950

Для обоснования лимитирующей стадии редокс-сорбции кислорода на катодно поляризуемом медьсодержащем нанокомпозите на основе ионообменной матрицы и регулирования скорости процесса необходимо определить значение предельного тока и рассмотреть влияние величины поляризующего тока на скорость поглощения кислорода в допредельной области поляризации тонкого зернистого слоя нанокомпозита.

Для получения значения предельного тока фракция гранулированного нанокомпозитного материала загружалась в катодное отделение сорбционно-мембранной электрохимической ячейки, которая состояла из двух анодных отделений с платиновыми анодами, отделенными от катодного катионообменными мембранами МК-40. Катод представлял собой зернистый слой пористого медьионообменного нанокомпозита $\mathrm{Cu}^{0}$. Lewatit K2620 в натриевой ионной форме с токоподводом из тонкой медной проволоки. Анодные отделения содержали сульфокатионообменник Lewatit K2620. Сульфокатионообменные мембраны МК-40 обеспечивали электропроводность и направленный перенос образующихся ионов водорода из анодных камер в катодную.

Кинетику электровосстановления кислорода из воды исследовали исследовали при поляризации постоянным током $I$ в течение 5 ч. По завершению опыта срезы зерен нанокомпозита исследовали микроскопически. Определяли геометрические границы промежуточной $\xi_{l}\left(\mathrm{Cu} / \mathrm{Cu}_{2} \mathrm{O}\right)$ и конечной $\xi_{2}\left(\mathrm{Cu}_{2} \mathrm{O} / \mathrm{CuO}\right)$ стадий последовательной химической реакции окисления металлического компонента нанокомпозита

Исследован процесс редокс-сорбции молекулярного кислорода из воды на тонком зернистом слое нанокомпозита медь-сульфокатионообменник при различных токах. Определено значение предельного диффузионного тока по кислороду для нового материала $\mathrm{Cu}^{0} \cdot$ Lewatit K2620. Показана существенная зависимость предельного тока от степени окисления наночастиц меди, свидетельствующая об их высокой химической активности. После нескольких последовательных вольтамперных циклов достигнута устойчивая активация наночастиц, которой соответствует максимальное значение эффективного предельного тока. Установлено, что в допредельной области при малых токах основную долю в поглощении кислорода составляет химическая компонента: убыль кислорода происходит за счет химического восстановления наночастицами меди, процесс лимитируется стадией внутренней диффузии. С повышением тока количество поглощенного кислорода возрастает, основную долю составляет электрохимическая компонента: убыль кислорода происходит за счет восстановления током, процесс вытесняется из внутридиффузионной области лимитирования во внешнедиффузионную, обеспечивающую более высокую скорость. Частично ток начинает расходоваться на электровосстановление образующихся оксидов меди.

Ключевые слова: наночастицы металла, металл-ионообменный нанокомпозит, редокссорбция кислорода, электрохимическая поляризация.

\section{Введение}

Скорость и механизм электровосстановления молекулярного кислорода изменяются в зависимости от материала электрода за счет различных электрокаталитиче- 
ских свойств [1-5]. Авторы [6,7] утверждают, что процесс электровосстановления кислорода на компактной меди протекает согласно четырехэлектронному механизму и лимитируется стадией диффузии кислорода. Переход к нанодисперсному состоянию может привести к тому, что восстановление кислорода будет протекать через двухстадийные двухэлектронные процессы на электроде, представляющем собой наночастицы меди, осажденные в ионообменную матрицу Nafion и нанесенные пленочной оболочкой на стеклоуглерод [8]. Такой электрод показывает более высокую стабильность при восстановлении кислорода в нейтральных растворах, что может найти применение в топливных элементах.

Электровосстановление молекулярного кислорода, растворенного в воде, перспективно осуществлять на гранулированных металл-ионообменных нанокомпозитах с целью удаления кислорода из воды [9]. Протекающие при электрохимической поляризации процессы можно продемонстрировать на схеме:

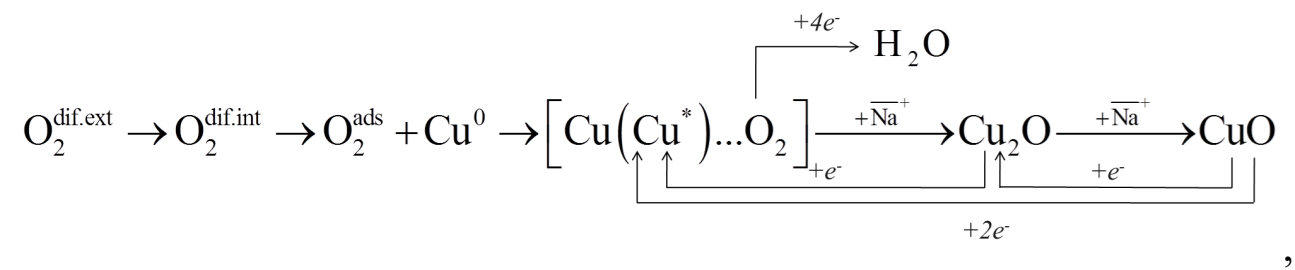

где $\overline{\mathrm{Na}}^{+}$- противоионы сульфокатионообменной матрицы, $\mathrm{Cu}^{*}-$ свежевосстановленная активированная медь.

На тонкопленочных нанокомпозитных электродах отмечена [10] важная роль природы, содержания и химической активности металлического компонента в плане обеспечения электронной проводимости композита и возможности сопутствующих электровосстановлению кислорода процессов. На тонких зернистых слоях нанокомпозитов установлено $[9,11]$ ускорение поглощения кислорода под одновременным воздействием электрохимической поляризации и химической активности нанокомпозита. Со временем происходит рост количества электрорегенерируемой меди из образующихся оксидов, способной вновь к взаимодействию с кислородом.

Для обоснования лимитирующей стадии редокс-сорбции кислорода на катодно поляризуемом медьсодержащем нанокомпозите и регулирования скорости электровосстановления растворенного в воде кислорода необходимо определить значение предельного тока и рассмотреть влияние величины поляризующего тока на скорость процесса в допредельной области поляризации тонкого зернистого слоя нанокомпозита.

\section{Экспериментальная часть}

Редокс-сорбцию молекулярного кислорода из проточной дистиллированной воды проводили на тонком зернистом слое нанокомпозита (НК) медьсульфокатионообменник. Химическое осаждение металла в гранулы моно- и макропористого сильнокислотного ионообменника Lewatit K2620 (Германия) был выполнен по механизму ионообменного насыщения и реагентного восстановления [10]. Емкость по металлу синтезированного нанокомпозита составила $\varepsilon_{\text {Me }^{0}}=9.6$ мэкв $/ \mathrm{cm}^{3}$. Эта величина обеспечивает сверхперколяционную электронную проводимость. Размер частиц металла был определен методом сканирующей электронной микроскопии $(\mathrm{CЭМ)} \mathrm{и} \mathrm{рентгенофазовым} \mathrm{анализом} \mathrm{(РФА).} \mathrm{Частицы} \mathrm{меди} \mathrm{в} \mathrm{большей} \mathrm{мере} \mathrm{со-}$ средоточены на поверхности и в приповерхностных слоях гранулы нанокомпозита. Физико-химические свойства синтезированных материалов приведены в табл. 1.

Кравченко и др. / Сорбционные и хроматографические процессы. 2020. Т. 20. № 4. С. 434-444 
Таблица 1. Физико-химические характеристики металл - ионообменного нанокомпозита $\mathrm{Cu} \cdot$. Lewatit K2620.

Table 1. Physico-chemical characteristics of the metal - ion-exchanger nanocomposite $\mathrm{Cu} u^{0}$ Lewatit K2620.

\begin{tabular}{|c|c|}
\hline Полимерная основа & Сшитый полистирол \\
\hline Диаметр гранул $d$, см & $0.04-0.10$ \\
\hline Размер пор, нм & 41 \\
\hline Ионообменная емкость $\varepsilon_{H^{+}}$, мэкв·см${ }^{-3}$ & 1.9 \\
\hline Емкость по меди $\varepsilon_{C u^{0}}$, мэкв· см$^{-3}$ & $9.6 \pm 0.1$ \\
\hline Размер частиц металла (СЭМ), нм & $170 \pm 15$ \\
\hline Размер частиц металла (РФА), нм & $17 \pm 1$ \\
\hline $\begin{array}{c}\text { Масса металла } m \text {, мас.\%, радиально распределенного по } \\
\text { грануле радиусом } R_{0}\end{array}$ & $30,6\left(R_{0}\right), 13.9\left(0.5 R_{0}\right), 4.4(R=0)$ \\
\hline
\end{tabular}

Для получения значения предельного тока фракция гранулированного нанокомпозитного материала загружалась в катодное отделение сорбционно-мембранной электрохимической ячейки (рис.1), которая состояла из двух анодных отделений с платиновыми анодами, отделенными от катодного катионообменными мембранами МК-40. Катод представлял собой зернистый слой пористого медь-ионообменного нанокомпозита $\mathrm{Cu}^{0}$. Lewatit $\mathrm{K} 2620$ в натриевой ионной форме с токоподводом из тонкой медной проволоки. Анодные отделения содержали сульфокатионообменник Lewatit K2620. Сульфокатионообменные мембраны МК-40 обеспечивали электропроводность и направленный перенос образующихся ионов водорода из анодных камер в катодную. Высота тонкого слоя нанокомпозита составляла $L=1.0 \cdot 10^{-2} \mathrm{M}$, сечение слоя нанокомпозита $S_{c e u}=1.2 \cdot 10^{-4} \mathrm{~m}^{2}$. Капилляр Луггина подводился непосредственно к медному токоподводу в середине катодной камеры. В качестве электрода сравнения использовали хлоридсеребряный электрод. Для определения предельного тока поляризационные кривые получались на тонком зернистом слое нанокомпозита $\mathrm{Cu}^{0} \cdot$ Lewatit K2620 $\left(\mathrm{Na}^{+}\right)$в $0.05 \mathrm{M}$ растворе $\mathrm{Na}_{2} \mathrm{SO}_{4}$ при заданной скорости его протока. Раствор пропускался через электролизер снизу вверх с линейной скоростью $u=0.23 \cdot 10^{-2} \mathrm{M} / \mathrm{c}$.

Поляризацию проводили от универсального источника питания Б5-47 (Россия). Выдержка при каждом значении тока составляла 2 мин. Сила тока регистрировалась миллиамперметром В7-58/1 (Россия), потенциал измеряли вольтметром универсальным GDM-78341 (Россия). Одновременно фиксировали концентрацию окислителя на входе и выходе из зернистого слоя анализатором кислорода АКПМ-01 (Россия), который был защищен металлической сеткой от внешних электромагнитных полей. Концентрация кислорода в растворе поддерживали постоянной в течение опыта путем непрерывного аэрирования атмосферным воздухом. Значение водородного показателя воды на выходе из катодного отделения определяли с помощью иономера АНИОН-4100 (Россия).

Из серии циклических вольтамперных кривых выбирали такие, на которых максимально четко был распознаваем предельный ток. Поляризационные кривые получались обратным ходом сразу же после активации в прямом ходе, чтобы металлический компонент композита как можно меньше окислялся. Значение плотности предельного диффузионного тока по кислороду $i_{\lim }(0)$ было найдено как отношение экспериментально полученного значения предельного тока $I_{\lim }$ и площади геометрической поверхности насыпного электрода $S_{3}$, расчет которой проводили по уравнению

Кравченко и др. / Сорбционные и хроматографические процессы. 2020. Т. 20. № 4. С. 434-444 


$$
S_{3}=\frac{3 \chi V}{R_{0}}
$$

где $\chi$ - коэффициент наполнения колонки зернистым нанокомпозитом, $V$ - объем загрузки, $R_{0}-$ радиус зерна НК.

Кинетику электровосстановления кислорода из воды исследовали исследовали в той же сорбционно-мембранной ячейке (рис. 1) на тонком зернистом слое нанокомпозита. Вода, насыщенная кислородом воздуха, пропускалась через электролизер снизу вверх с линейной скоростью $u=0.23 \cdot 10^{-2} \mathrm{M} / \mathrm{c}$. Поляризацию проводили постоянным током $I$ в течение 5 ч. По завершению опыта срезы зерен нанокомпозита исследовали при помощи цифрового микроскопа DigiMicro 2.0 (Китай) при 200кратном увеличении. Отмечали геометрические границы промежуточной $\xi_{1}\left(\mathrm{Cu} / \mathrm{Cu}_{2} \mathrm{O}\right)$ и конечной $\xi_{2}\left(\mathrm{Cu}_{2} \mathrm{O} / \mathrm{CuO}\right)$ стадий последовательной химической реакции окисления металлического компонента нанокомпозита, где $\xi_{1}=R_{1} / R_{0}$ и $\xi_{2}=R_{2} / R_{0}$; $R_{1}, R_{2}$ - радиусы оксидов меди (I) и (II) соответственно. В срезе зерна НК металл и его оксиды имеют различную окраску: $\mathrm{Cu}$ - темнокоричневую, $\mathrm{Cu}_{2} \mathrm{O}$ - светлокоричневую, $\mathrm{CuO}$ - черную.

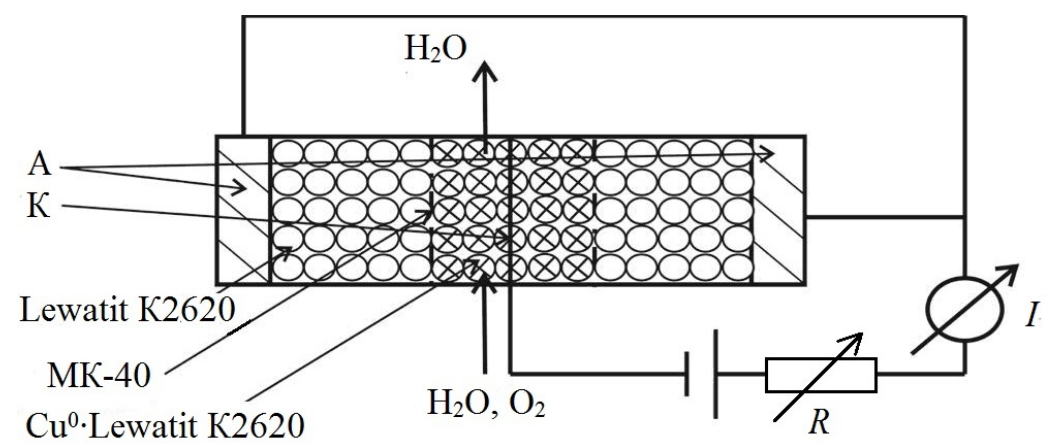

Рис. 1. Схема трехкамерного сорбционно-мембранного электролизера с насадкой нанокомпозита в катодной камере для восстановления кислорода, растворенного в воде: $\mathrm{K}$ - проволочный медный катод, $\mathrm{Cu}^{0} \cdot$ Lewatit $\mathrm{K} 2620$ - насыпной слой

HК; А - платиновые аноды, Lewatit К2620 - насыпные слои сульфокатионообменника; МК-40 - катионообменная мембрана; $I$ - источник тока; $R$ - регулируемое сопротивление.

Fig. 1. A three-section adsorption-membrane electrochemical cell with a nanocomposite in the cathode section used to reduce oxygen from water: $\mathrm{K}$ - copper wire cathode, $\mathrm{Cu}^{0}$. Lewatit K2620 - filling layer of the nanocomposite; A - platinum anodes, Lewatit K2620 - saturated layers

of the sulfocation-exchanger; MK-40 - cation-exchange membrane; $I$ - current source; $R$ - variable resistance.

Для выбора значения поляризующего тока использовали подход, изложенный ранее [12]. В его основу положены представления о внешнедиффузионном переносе кислорода и плотности предельного диффузионного тока по кислороду. Кинетические параметры этого процесса определяют максимальное различие концентрации кислорода на входе и выходе воды из зернистого слоя и соответственно силу максимально допустимого тока для поляризации, т.е. предельного тока $I_{\lim }(L)$ на зернистом слое высотой $L$,

$$
I_{\text {lim }}(L)=I_{\text {com }} \frac{A L}{1+A L},
$$

где $I_{\text {com }}$ - общий ток, необходимый для восстановления всего поступающего на колонну окислителя

$$
I_{\text {com }}=n F S u c_{0},
$$


$n$ - число электронов, участвующих в реакции, которое равно $4 ; F$ - постоянная Фарадея; $S$ - площадь сечения зернистого слоя; $u$ - линейная скорость протока воды; $c_{o}-$ концентрация кислорода на входе в зернистый слой НК.

Постоянная $A$ вычисляется по формуле

$$
A=\frac{3 \chi i_{\lim }(0)}{n F u R_{0} c_{0}}
$$

где $i_{\text {lim }}(0)$ - плотность предельного диффузионного тока по кислороду на входе в зернистый слой НК.

\section{Обсуждение результатов}

Предельный ток. Значения предельных токов были найдены из поляризационных кривых (рис. 2) графическим методом при различной концентрации растворенного кислорода. После химической регенерации зерен нанокомпозита эксперимент был повторен. Восстановление привело к еще большей активации НК. По концентрации кислорода на входе и выходе из зернистого слоя определена концентрация кислорода в месте расположения капилляра Луггина, т.е. на середине высоты зернистого слоя.

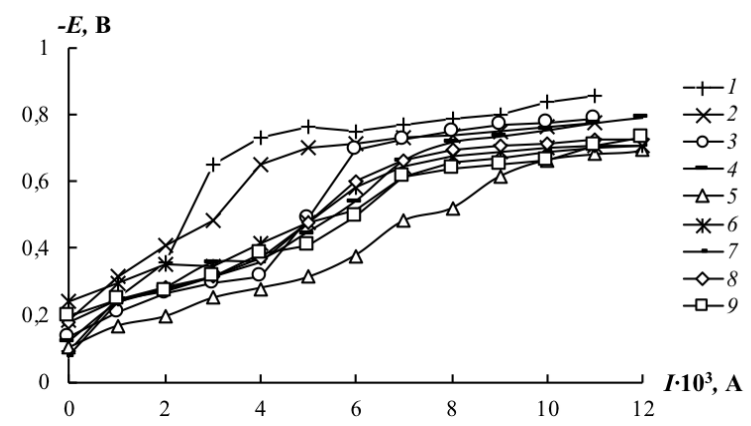

Рис. 2. Катодные поляризационные кривые обратного хода на $\mathrm{Cu}^{0} \cdot$ Lewatit K2620 в $0.05 \mathrm{M}$ водном растворе $\mathrm{Na}_{2} \mathrm{SO}_{4}$ при концентрации растворенного кислорода на середине высоты зернистого слоя $c(L / 2)$, $\mathcal{M} / \partial \mathcal{M}^{3}: 1-7.08 ; 2-7.45 ; 3-7.69 ; 4-7.27$; $5-7.46 ; 6-7.30 ; 7-6.67 ; 8-6.51 ; 9-7.29$. Цифрами 1-9 обозначены последовательные циклические кривые.

Fig. 2. Cathodic polarization recoil curves on $\mathrm{Cu}^{0}$. Lewatit $\mathrm{K} 2620$ in a $0.05 \mathrm{M}$ water solution of $\mathrm{Na}_{2} \mathrm{SO}_{4}$ with the concentration of the dissolved oxygen being half the height of the granular layer $c(L / 2), m g / l: 1-7.08 ; 2-7.45$; 3 - 7.69; 4-7.27; 5-7.46; 6- 7.30; 7 - 6.67;

$8-6.51 ; 9-7.29 .1-9$ mark the successive cyclic curves

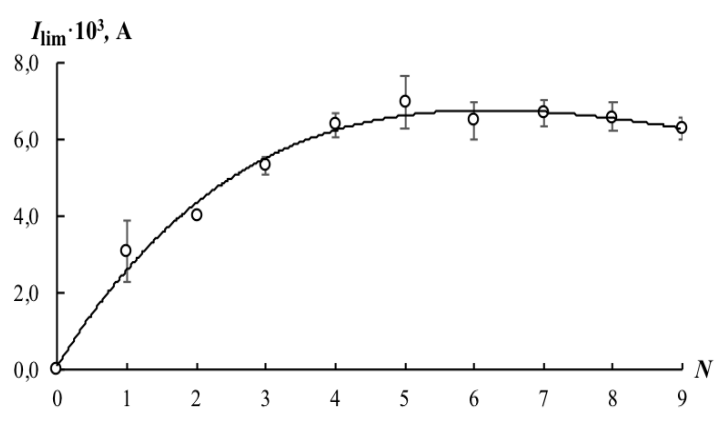

Рис. 3. Зависимость силы предельного тока $I_{\lim }$ по кислороду на нанокомпозитах $\mathrm{Cu}^{0}$.Lewatit K2620 от числа последовательных циклов поляризации $N$.

Fig. 3. Dependence of the maximum current $I_{\text {lim }}$ going through oxygen on nanocomposites $\mathrm{Cu}^{0}$. Lewatit K2620 on the number of successive polarisation cycles $N$.

Сила предельного тока $I_{\lim }$ в начале эксперимента (циклы 1-3) имеет низкие значения, т.к. происходит контакт зерен с воздухом. Нанокомпозит окисляется, что препятствует катодному восстановлению кислорода. В дальнейшем при росте числа циклов катодной поляризации нанокомпозит активируется, $I_{\lim }$ достигает максимального значения и составляет $(6.5 \pm 0.5) \cdot 10^{-3} \mathrm{~A}$ (рис. 3). Весь ток расходуется практиче- 
ски на восстановление кислорода, а не оксидов меди. Для заданных условий эксперимента среднем радиусе зерна $R_{0}=0.035 \mathrm{~cm}$, коэффициенте заполнения зернами катодной камеры $\chi=0.66$ и фактической площади поверхности зерен в исследуемой ячейке, рассчитанной согласно уравнению (2), с помощью гальваностатического метода определено значение предельной диффузионной плотности тока $i_{\lim }(0)=$ $(1.0 \pm 0.1) \mathrm{A} / \mathrm{M}^{2}$ при концентрации кислорода в исходном растворе $c_{0}=0.23 \pm$ 0.01 моль $/ \mathrm{M}^{3}$, что соответствует аналогичным величинам плотности тока $i_{\lim }(0)=(1.0 \pm 0.2) \mathrm{A} / \mathrm{m}^{2}$, полученным для медьсодержащего нанокомпозита на основе КУ-23 [12].

Кинетика восстановления кислорода. Полученное значение плотности предельного диффузионного тока использовали для расчета максимально допустимой силы тока $I_{\lim }(L)$, необходимой для восстановления кислорода на зернистом слое. Расчет проведен по формуле (3). При выбранных условиях величина $I_{\lim }(L)=$ $5.4 \cdot 10^{-3} \mathrm{~A}$. Кинетику восстановления кислорода, растворенного в воде, исследовали при различных силах катодного тока $I$, не превышаюших $I_{\lim }(L)$. Значения концентрации кислорода в воде на выходе из зернистого слоя НК для различных режимов катодной поляризации в течение 5 ч. представлены на рис. $4 a$. Как видно, внешний поляризующий ток оказывает существенное влияние на концентрацию кислорода на выходе. Водородный показатель воды несколько увеличивается с повышением поляризующего тока (рис. 4б).
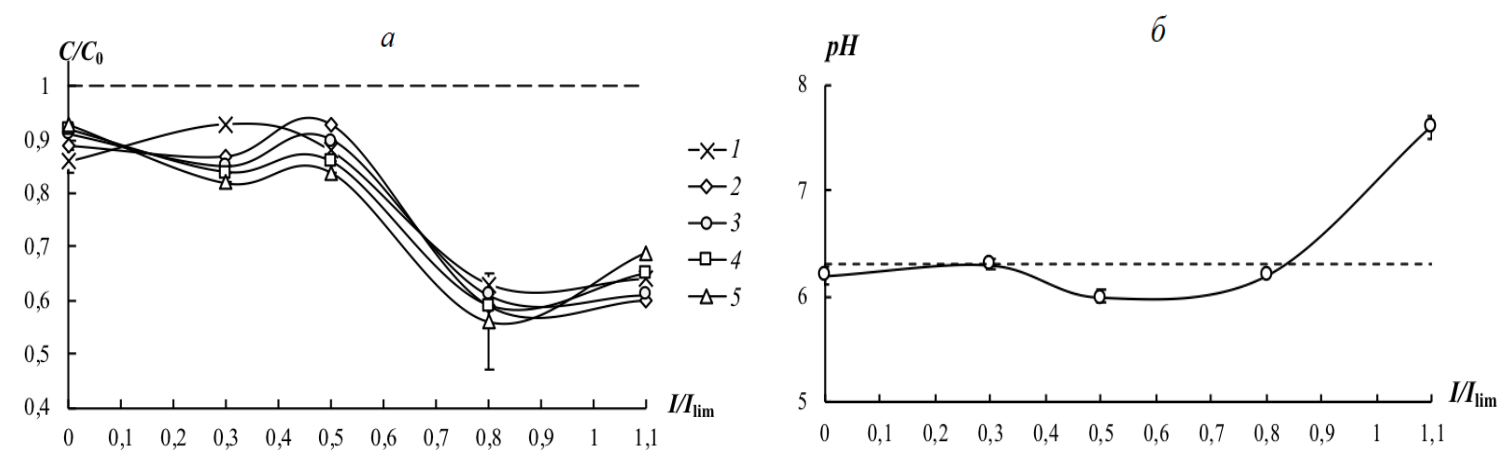

Рис. 4. Зависимость относительной концентрации $C / C_{0}$ растворенного в воде кислорода (a) и $p H$ воды на выходе (б) для тонкого зернистого слоя $\mathrm{Cu}^{0} \cdot$ Lewatit K2620 от относительной силы тока $I / I_{\text {lim }}(L)$ для времени $t$, ч: $1-1 ; 2-2 ; 3-3 ; 4-4 ; 5-5$. $C_{0}-$ концентрация кислорода в исходной воде. Пунктирными линиями обозначены показатели исходной.

Fig. 4. Dependence of the relative concentration $C / C_{0}$ of the oxygen dissolved in water $(a)$ and the output $p H$ of water $(b)$ for a thin granular layer of $\mathrm{Cu}^{0} \cdot$ Lewatit $\mathrm{K} 2620$ on the relative current strength $I / I_{\text {lim }}(L)$ for the time $t$, h: $1-1 ; 2-2 ; 3-3 ; 4-4 ; 5-5$. $C_{0}$ - initial oxygen concentration in water. Dotted lines show the initial values.

Соответственно зависимость количества поглощенного кислорода $Q$ от значения поляризующего тока имеет экстремальный вид, причем, со временем максимум все более выражен (рис. 5). Наибольшее количество поглощенного кислорода наблюдается при относительном токе $I / \lim (L)=0.44$. Возрастание количества поглощенного кислорода обусловлено, в первую очередь, восстановлением его за счет тока катодного направления, а также восстановлением за счет химического окисления наночастиц металла. Однако дальнейшее снижение $Q$, вероятнее всего, связано с затратой тока на электровосстановление образующихся продуктов окисления наночастиц - оксидов меди. Побочной реакции электровыделения водорода при заданных токах не наблюдается. 


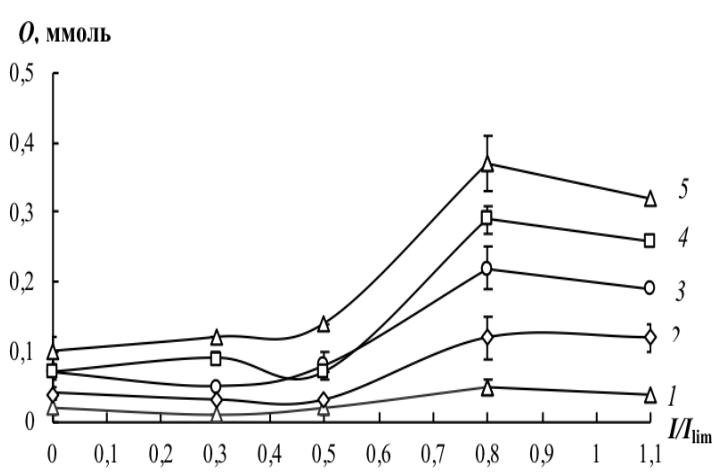

Рис. 5. Зависимость количества поглощенного кислорода $Q$ из воды нанокомпозитом $\mathrm{Cu}^{0} \cdot$ Lewatit $\mathrm{K} 2620$ от $I / I_{\lim }(L)$ в течение времени $t$, ч:

$1-1 ; 2-2 ; 3-3 ; 4-4 ; 5-5$.

Fig. 5. Dependence of the amount of oxygen $Q$ absorbed by the nanocomposite

$\mathrm{Cu}^{0} \cdot$ Lewatit $\mathrm{K} 2620$ from water on $I / I \lim (L)$ for the time $t$, h: $1-1 ; 2-2 ; 3-3 ; 4-4 ; 5-5$.

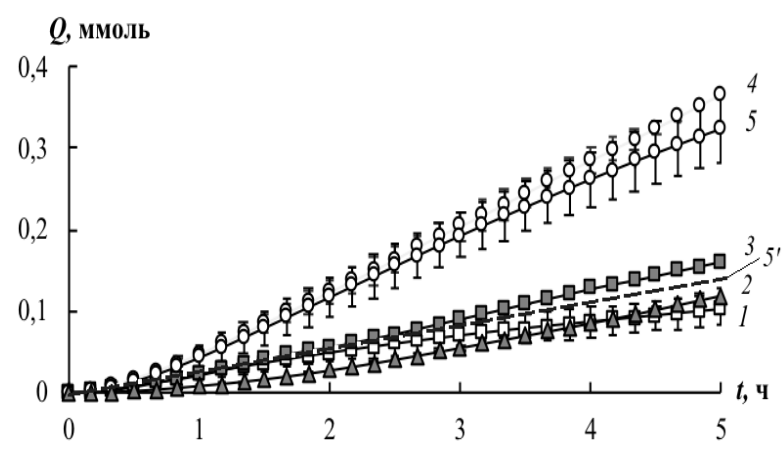

Рис. 6. Кинетические зависимости количества поглощенного кислорода $Q$ из воды тонким зернистым слоем нанокомпозита $\mathrm{Cu}^{0} \cdot$ Lewatit K2620 от времени при относительной силе тока $I / \lim (L): 1-0,2-0.19$; $3-0.28 ; 4-0.44 ; 5,5^{\prime}-0.57$. Кривая, обозначенная штрихом, соответствуют расчету по закону Фарадея.

Fig. 6. Kinetic dependencies of the amount of oxygen $Q$ absorbed from water by the thin granu-

lar layer of the nanocomposite $\mathrm{Cu}^{0} \cdot$ Lewatit

K2620 on the time with the relative current strength being $I / I_{\lim }(L): 1-0,2-0.19 ; 3-0.28$; $4-0.44 ; 5,5^{\prime}-0.57$. The curve of the dashed line complies with Faraday's law.

Химическая компонента процесса при этом составляет существенную долю, так как в течение времени эксперимента медьсодержащий НК остается высокоактивным, что наглядно видно из сопоставления экспериментальных и теоретических кинетических кривых (рис. 6). Полное количество поглощенного кислорода явно преобладает над рассчитанным по закону Фарадея.

Электрохимический и химический вклады. Для определения соотношения электрохимического и химического вкладов в поглощение кислорода рассмотрим полученные экспериментальные данные о пространственных координатах химических стадий окисления $\xi_{1}\left(\mathrm{Cu} / \mathrm{Cu}_{2} \mathrm{O}\right)$ и $\xi_{2}\left(\mathrm{Cu}_{2} \mathrm{O} / \mathrm{CuO}\right)$ в бестоковом режиме и при внешней катодной поляризации зернистого слоя медьсодержащего нанокомпозита, приведенные в табл. 2. Изменение положения границ отдельных стадий химической реакции окисления меди происходило неравномерно с преимущественным образованием оксида металла (I). Степень полноты окисления нанокомпозита $\alpha_{\mathrm{x}}$ за счет химического взаимодействия кислорода с наночастицами меди вычисляли по формуле [12]

$$
\alpha_{\mathrm{x}}=1-\frac{\xi_{1}^{3}+\xi_{2}^{3}}{2}
$$

связывающей данную величину с безразмерными координатами отдельных стадий химической реакции окисления меди.

В качестве критерия оценки парциальных вкладов химического и электрохимического маршрутов процесса восстановления кислорода использовали количество поглощенного нанокомпозитом кислорода $Q$ (рис. 5). Рассчитывали количество хи-

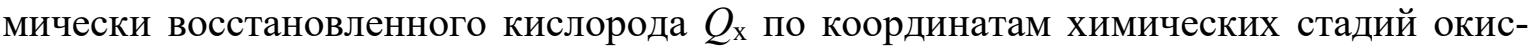
ления наночастиц $\xi_{1}$ и $\xi_{2}$ и степени окисления $\alpha_{\mathrm{x}}$. Вклад химической составляющей $\omega_{x}$, который обусловлен окислением наночастиц меди композитного материала, 
найден как отношение количества химически восстановленного кислорода к общему количеству поглощенного $\mathrm{O}_{2}$ к данному моменту времени

$$
\omega_{\mathrm{x}}=\frac{Q_{\mathrm{x}}}{Q} .
$$

Таблица 2. Значения безразмерных (отнесенных к радиусу зерна $R_{0}$ ) пространственных координат $\xi_{1}$ и $\xi_{2}$ реакции стадийного окисления медьсодержащего нанокомпозита $\mathrm{Cu}^{0} \cdot$ Lewatit $\mathrm{K} 2620\left(\mathrm{Na}^{+}\right)$. Время эксперимента 5 ч.

Table 2. Values of the dimensionless (corresponding to the granule's radius $R_{0}$ ) spatial coordinates $\xi_{1}$ and $\xi_{2}$ of the reaction of stage oxidation of the copper-containing nanocomposite $\mathrm{Cu}^{0}$. Lewatit $\mathrm{K} 2620\left(\mathrm{Na}^{+}\right)$. The experiment lasted 5 hours.

\begin{tabular}{|c|c|c|c|c|}
\hline $\begin{array}{c}\text { Сила поляризую- } \\
\text { щего тока } \\
I \cdot 10^{3}, \mathrm{~A}\end{array}$ & $I / I_{\text {lim }}$ & $\begin{array}{c}\text { Границы проме- } \\
\text { жуточной ста- } \\
\text { дии, } \xi_{1}\end{array}$ & $\begin{array}{c}\text { Границы } \\
\text { конечной } \\
\text { стадии, } \xi_{2}\end{array}$ & $\begin{array}{c}\text { Степень химиче- } \\
\text { ского окисления } \\
\text { НК, } \alpha_{x}\end{array}$ \\
\hline 0 & 0 & $0.92 \pm 0.02$ & 1.00 & $0.11 \pm 0.02$ \\
\hline 1.0 & 0.19 & $0.94 \pm 0.02$ & 1.00 & $0.08 \pm 0.02$ \\
\hline 1.5 & 0.28 & $0.94 \pm 0.01$ & 1.00 & $0.08 \pm 0.01$ \\
\hline 2.4 & 0.44 & $0.96 \pm 0.02$ & 1.00 & $0.06 \pm 0.02$ \\
\hline 3.1 & 0.57 & $0.96 \pm 0.02$ & 1.00 & $0.06 \pm 0.02$ \\
\hline
\end{tabular}

Вклад электрохимической компоненты $\omega_{э x}$ был рассчитан по разности общего количества поглощенного и химически восстановленного кислорода. Полученные значения химического и электрохимического вкладов представлены в табл. 3. Из нее следует, что нанокомпозит сохраняет свою высокую химическую активность при малых токах. Вклад электрохимической составляющей процесса восстановления кислорода повышается в связи с ростом прошедшего через систему тока. Основываясь на подчинении процесса электровосстановления кислорода на нанокомпозите уравнению Левича [11], можно полагать, что процесс восстановления $\mathrm{O}_{2}$ в основном локализуется на поверхности. Если без катодной поляризации превалирует стадия внутренней диффузии кислорода, то под током - внешней диффузии.

Таблица 3. Материальный баланс в процессе электровосстановления молекулярного кислорода тонким зернистым слоем $\mathrm{Cu}^{0} \cdot$ Lewatit $\mathrm{K} 2620\left(\mathrm{Na}^{+}\right)$при катодной поляризации и вклады химической $\omega_{\mathrm{x}}$ и электрохимической $\omega_{э x}$ компонент процесса восстановления кислорода. Время эксперимента 5 ч.

Table 3. Material balance during the electroreduction of molecular oxygen by a thin granular layer of $\mathrm{Cu}^{0} \cdot$ Lewatit $\mathrm{K} 2620\left(\mathrm{Na}^{+}\right)$using cathodic polarisation and the contributions of the chemical $\omega_{\text {ch }}$ and electrochemical $\omega_{\text {elch }}$ components of the oxygen reduction process. The experiment lasted 5 hours.

\begin{tabular}{|c|c|c|c|c|c|c|}
\hline \multirow{2}{*}{$\begin{array}{c}\text { Сила по- } \\
\text { ляризую- } \\
\text { щего тока }\end{array}$} & \multirow{2}{*}{$\begin{array}{c}I / I_{\lim } \\
I \cdot 10^{3}, \mathrm{~A}\end{array}$} & & \multicolumn{2}{|c|}{ Количество восстановленного кислорода, $Q}$, & \multirow{2}{*}{ ммоль } & \multirow{2}{*}{$\omega_{\text {эх }} \%$} \\
\cline { 3 - 6 },$\%$ & $\begin{array}{c}\text { Экспери- } \\
\text { ментально } Q\end{array}$ & $\begin{array}{c}\text { Химически } \\
Q_{x}\end{array}$ & $\begin{array}{c}\text { Электрохимически } \\
Q_{э x}\end{array}$ & & \\
\hline 0 & 0 & 0.10 & 0.17 & - & 100 & 0 \\
\hline 1.0 & 0.19 & 0.12 & 0.13 & - & 100 & 0 \\
\hline 1.5 & 0.28 & 0.16 & 0.13 & 0.03 & 81.3 & 18.7 \\
\hline 2.4 & 0.44 & 0.37 & 0.09 & 0.28 & 24.3 & 75.7 \\
\hline 3.1 & 0.57 & 0.32 & 0.09 & 0.24 & 28.1 & 71.9 \\
\hline
\end{tabular}

Поскольку при заданных токах электрохимический процесс восстановления кислорода протекает в допредельном режиме, то возможны следующие пути, по ко- 
торым расходуется электрический ток, - на восстановление кислорода и образующихся оксидов меди. Парциальные составляющие процесса приведены в табл. 4.

Таблица 4. Выход по току для кислорода $\eta_{\mathrm{T}}\left(\mathrm{O}_{2}\right)$ и оксидов меди $\eta_{\mathrm{T}}($ окс $)$ на $\mathrm{Cu}^{0} \cdot$ Lewatit $\mathrm{K} 2620\left(\mathrm{Na}^{+}\right)$. Время эксперимента 5 ч.

Table 4. Current efficiency for oxygen $\eta_{\mathrm{T}}\left(\mathrm{O}_{2}\right)$ and copper oxides $\eta_{\mathrm{T}}(\mathrm{ox})$ on $\mathrm{Cu}^{0}$. Lewatit $\mathrm{K} 2620\left(\mathrm{Na}^{+}\right)$. The experiment lasted 5 hours.

\begin{tabular}{|c|c|c|c|c|c|}
\hline $\begin{array}{c}\text { Сила поляризую- } \\
\text { щего тока }-I \cdot 10^{3}, \mathrm{~A}\end{array}$ & $I / I_{\text {lim }}$ & $q$, Кл & $q\left(\mathrm{O}_{2}\right), \mathrm{Kл}$ & $\eta_{\mathrm{T}}\left(\mathrm{O}_{2}\right), \%$ & $\eta_{\mathrm{T}}(\mathrm{o \kappa c}), \%$ \\
\hline 1.0 & 0.19 & 18.0 & 19.3 & - & - \\
\hline 1.5 & 0.28 & 27.0 & 27.0 & 100 & 0 \\
\hline 2.4 & 0.44 & 43.2 & 42.5 & 98.4 & 1.6 \\
\hline 3.1 & 0.57 & 55.8 & 54.0 & 96.8 & 3.2 \\
\hline
\end{tabular}

Учитывая закон Фарадея, рассчитана разность зарядов, прошедших через систему $q$ и затраченных на электровосстановление кислорода $q\left(\mathrm{O}_{2}\right)$, чему соответствует заряд, пошедший на восстановление оксидов $q$ (окс). Выход по току по кислороду найден по уравнению

$$
\eta_{\mathrm{T}}\left(\mathrm{O}_{2}\right)=\frac{n F\left(Q-Q_{\mathrm{x}}\right)}{q} .
$$

Выход по току близок к предельному значению. В ходе эксперимента (5 ч) с ростом плотности тока несколько уменьшается выход по току в целевой реакции электровосстановления кислорода (до 97\%). Однако основной расход электроэнергии на электрическое восстановление кислорода очевиден.

\section{Заключение}

Определено значение предельного диффузионного тока по кислороду для нового медьсодержащего нанокомпозита, синтезированного на макро- и монопористом сульфокатионообменнике Lewatit K2620. Показано, что особенностью кинетики процесса поглощения кислорода является одновременное течение электрохимического, обусловленного током, и химического, обусловленного металлическими наночастицами, маршрутов восстановления кислорода на гранулированном слое металл-ионообменного нанокомпозита. Химическая компонента процесса восстановления кислорода на наночастицах меди составляет существенную долю. Вклад электрохимической составляющей повышается с ростом тока, вытесняясь из внутридиффузионной области лимитирования во внешнедиффузионную. С повышением поляризующего тока количество поглощенного кислорода увеличивается, наблюдается сопутствующий процесс электровосстановления образующегося оксида меди (I).

Микроскопические и рентгеновские исследования выполнены в Центре коллективного пользования на научном оборудовании ВГУ. Исследования поддержаны Российским фондом фундаментальньх исследований (код проекта № 20-08-00404a).

\section{Список литературы}

1. Shao M. // Electrocatalysis in Fuel Cells, Catalysts. 2015. Vol. 5. pp. 2115-2121. DOI: $10.3390 /$ catal5042115
2. Гуревич С.А., Ильющенко Д.С., Явсин Д.А. и др. // Электрохимия. 2017. Т. 53. № 6. С. 642-650. 
3. Nie Y., Li L., Wei Z. // Chem. Soc. Rev., 2015, Vol. 44, pp. 2168-2201. DOI: $10.1039 / \mathrm{c} 4 \mathrm{cs} 00484 \mathrm{a}$

4. Богдановская В.А., Тарасевич М.Р. // Электрохимия. 2011. Т. 47. № 4. С. 404-410.

5. Кондратьев В.В., Малев В.В., Елисеева С.Н. // Успехи химии. 2016. Т. 85. № 1. С. 14-37.

6. Lu Y., Xu H., Jia Wang J. et al. // Electrochimica Acta. 2009, Vol. 54. pp. 3972-3978. DOI: 10.1016/j.electacta.2009.02.019

7. Vukmirovic M.B., Vasiljevic N., Dimitrov N. et al. // J. Electrochem. Soc. 2002. Vol. 150. pp. B10-B15. DOI: 10.1149/1.1526554
8. Selvaraju T., Ramaraj R. // Pramana J. Phys. 2005. Vol. 65. No 4. pp. 713-722.

9. Вахнин Д.Д., Придорогина В.Е., Полянский Л.Н. и др. // Журн. физич. химии. 2018. T. 92. № 1. С. 155-160.

10. Кравченко Т.А., Вахнин Д.Д., Придорогина В.Е. и др. // Электрохимия. 2019. Т. 55. № 12. С. 1524-1531.

11. Вахнин Д.Д., Полянский Л.Н., Кравченко Т.А. и др. // Журн. физич. химии. 2019. T.93. № 5. C. 749-756.

12. Кравченко Т.А., Полянский Л.Н., Калиничев А.И. и др. Нанокомпозиты металлионообменник. М. Наука. 2009. 391 с.

\title{
The role of electric current in the redox-sorption of oxygen by copper-containing nanocomposites
}

\author{
(C) 2020 Kravchenko T.A., Vakhnin D.D., Chumakova A.V., Shevtsova E.A.
}

\author{
Voronezh State University, Voronezh, Russia
}

In order to explain the limiting stage of the redox-sorption of oxygen on a cathode-polarised coppercontaining nanocomposite based on an ion exchange matrix and the regulation of the rate of the process, we need to determine the maximum current and study the influence of the polarisation current on the absorption rate of oxygen in the limiting polarization region of the thin granular layer of the nanocomposite.

To obtain the maximum current, we placed a fraction of the granular nanocomposite material into the cathode section of the adsorption-membrane electrochemical cell. The cell had two anode sections with platinum anodes separated from the cathode section by cation exchange membranes MK-40. The cathode was a granular layer of the porous copper-ion-exchange nanocomposite $\mathrm{Cu}^{0} \cdot$ Lewatit $\mathrm{K} 2620$ in the sodium ion form with the current leads made of thin copper wire. The anode sections contained a Lewatit K2620 sulfonic acid cation exchanger. MK-40 sulfonic acid cation exchanger membranes ensured the electrical conductivity and directional transport of hydrogen ions from the anode sections to the cathode.

The kinetics of oxygen electroreduction from water was studied during the polarisation with direct current $I$ for 5 hours. After that, the slices of the nanocomposite granules were studied under a microscope. We determined the geometric boundaries of the intermediate $\xi_{1}\left(\mathrm{Cu}_{/} \mathrm{Cu}_{2} \mathrm{O}\right)$ and final $\xi_{2}\left(\mathrm{Cu}_{2} \mathrm{O} / \mathrm{CuO}\right)$ stages of the successive oxidation reaction of the nanocomposite's metal component.

We also studied the redox-sorption of molecular oxygen from water on a thin granular layer of the copper-acid cation exchanger nanocomposite at different currents. The study determined the oxygen diffusion current for the new material $\mathrm{Cu}^{0}$. Lewatit $\mathrm{K} 2620$. It also revealed a strong dependence of the maximum current on the degree of oxidation of copper nanoparticles, which indicates their high chemical activity. After several successive volt-ampere cycles, we reached stable activation of nanoparticles corresponding to the maximum value of the effective maximum current. The study determined that in the limiting region with a low current, the most oxygen is absorbed by the chemical component: the amount of oxygen is reduced by means of reduction by copper nanoparticles. The process is limited by the internal diffusion stage. When we increase the current, the amount of absorbed oxygen also grows, with the electrochemical component playing the key role: the reduction of oxygen by the current is observed. The process is forced from the internal diffusion limiting region to the external diffusion, which ensures a faster rate. The current is partly used for the electroreduction of copper oxides.

Keywords: metal nanoparticles, metal - ion-exchange nanocomposite, redox-sorption of oxygen, electrochemical polarisation.

\section{References}

1. Shao M., Electrocatalysis in Fuel Cells, Catalysts, 2015, Vol. 5, pp. 2115-2121. DOI: $10.3390 /$ catal5042115
2. Gurevich S.A., Il'ushchenko D.S., Yavsin D. A. et al., Russ. J. Electrochem., 2017, Vol. 53, pp. 567-547. DOI: 


\subsection{4/S1023193517060052}

3. Nie Y., Li L., Wei Z., Chem. Soc. Rev., 2015, Vol. 44, pp. 2168-2201. DOI: $10.1039 / \mathrm{c} 4 \mathrm{cs} 00484 \mathrm{a}$

4. Bogdanovskaya V.A., Tarasevich M.R., Russ. J. Electrochem., 2011, Vol. 47, pp. 380386. DOI: $10.1134 / \mathrm{S} 1023193511040057$

5. Kondratiev V.V., Malev V.V., Eliseeva S.N., Russ. Chem. Reviews, 2016, Vol. 85, pp. 14-37. DOI: $10.1070 /$ RCR4509

6. Lu Y., Xu H., Jia Wang J. et al., Electrochimica Acta, 2009, Vol. 54, pp. 3972-3978. DOI: $10.1016 /$ j.electacta.2009.02.019

7. Vukmirovic M.B., Vasiljevic N., Dimitrov N. et al., J. Electrochem. Soc., 2002, Vol. 150, pp. B10-B15. DOI: 10.1149/1.1526554

8. Selvaraju T., Ramaraj R., Pramana $-J$.

Кравченко Тамара Александровна - д.Х.н., проф., кафедра физической химии, Воронежский государственный университет, Воронеж

Вахнин Дмитрий Дмитриевич - аспирант, кафедра физической химии, Воронежский государственный университет, Воронеж

Чумакова Алина Витальевна - магистр, кафедра физической химии, Воронежский государственный университет, Воронеж

Шевцова Екатерина Александровна - магистр, кафедра физической химии, Воронежский государственный университет, Воронеж
Phys., 2005, Vol. 65, No 4, pp. 713-722.

9. Vakhnin D.D., Pridorogina V.E., Polyanskii L.N. et al., Russ. J. Phys. Chem. A., 2018, Vol. 92, No 1, pp. 172-177. DOI: 10.1134/S0036024418010296

10. Kravchenko T.A., Vakhnin D.D, Pridorogina V.E. et al., Russ. J. Electrochem., 2019, Vol. 55, No 12, pp. 1251-1257. DOI: 10.1134/s1023193519120097

11. Vakhnin D.D., Polyanskii L.N., Kravchenko T.A. et al., Russ. J. Phys. Chem. A, 2019, Vol. 93, No 5, pp. 951-957. DOI: 10.1134/S0036024419050315

12. Kravchenko T.A., Polyanskii L.N., Kalinichev A.I. et al., Nanokompozity metallionoobmennik, M., Nauka, 2009, 391 p.

Kravchenko Tamara A. - PHD of chemistry, prof. Phsical Chemistry Department, Voronezh State University, Voronezh, E-mail: krav280937@yandex.ru

Vakhnin Dmitrii D. - graduate student of Physical Chemistry Department, Voronezh State University, Voronezh, E-mail: vakhnin.dima@,rambler.ru

Chumakova Alina V. - magister of Phsical Chemistry Department, Voronezh State University, Voronezh, e-mail: 7632111@rambler.ru

Shevtsova Ekaterina A. - magister of Physical Chemistry Department, Voronezh State University, Voronezh, E-mail: ekaterina10150@yandex.ru 